\title{
DIGESTIBILIDADE APARENTE DA DIETA SUPLEMENTADA COM CONCENTRADO DE LEVEDURAS VIVAS PARA AVESTRUZES EM CRESCIMENTO
}

\section{Apparent Digestibility of the Diet with Concentrated of Live Yeast Supplementation for Ostriches in Growth}

\author{
Joana D 'Arc Silveira Souza ${ }^{1}$ \\ Walter Motta Ferreira ${ }^{2}$ \\ Eloísa Simões Saliba \\ Carlos Eduardo do Prado Saad ${ }^{\overline{3}}$ \\ Luiz Carlos Machado 4 \\ José Renato Monteiro 5
}

\section{Resumo}

O objetivo do presente estudo foi avaliar a influência do concentrado de leveduras vivas sobre a digestibilidade dos princípios nutritivos na dieta de filhotes de avestruz em crescimento. Foram utilizados 36 animais com três meses de idade, distribuídos aleatoriamente em dois tratamentos, sendo um controle (TC) e outro com suplementação levedura (TL). A ração foi oferecida ad libitum em várias porções durante o dia e ao entardecer, as sobras foram pesadas e anotadas. Foram utilizados como indicadores externos o óxido crômico e o LPE®, para determinação dos valores do coeficiente de digestibilidade e da fração digestível dos princípios nutritivos, sendo este último validado para utilização como indicadorem avestruzes. $O$ período total do ensaio foi de doze dias, sendo sete dias de adaptação ao local e ao óxido crômico e cinco dias de colheita de fezes. Não houve diferença significativa $(\mathrm{P}>0,05)$ nos tratamentos para os valores do coeficiente de digestibilidade e fração digestível dos princípios nutritivos (MS, MO, FDN, PB, EE e EB). Dentre os indicadores, o LPE® apresentou um coeficiente de variação menor em relação ao óxido crômico para todos os parâmetros avaliados. Os valores mais confiáveis e que estão de acordo com os relatos da literatura foram os estimados pelo LIPE ${ }^{\circledR}$. O LPE ${ }^{\circledR}$ se mostrou um excelente indicador externo para avestruzes em fase de crescimento inicial.

Palavras-chave: Digestibilidade aparente, Avestruz, Indicador, Levedura viva.

Doutoranda em Ciência Animal. Departamento de Zootecnia, Escola de Veterinária, UFMG. Caixa postal 567. CEP 30123-970. Belo Horizonte. Minas Gerais. E-mail: joanadarc-1@hotmail.com, parte da dissertação de mestrado.

2 Professor Adjunto, EV/UFMG.

3 Professor Adjunto, Universidade Federal de Lavras.

4 Colaborador, Gerente Geral da SAF do Brasil, colaborador.

Doutorando, EV/UFMG, Colaborador. 


\section{Abstract}

The objective of the present study was to evaluate the influence of the concentrate of live yeast on the digestibility of the nutritious principles in the diet of ostrich nestlings in growth. Thirty six animals were used with three months old, distributed in two treatments, a control (TC) and other with yeast supplementation (TL). The diet was offered ad libitum, in several portions during the day, and at dusk the surpluses were weighted and registered. The oxide chromic and $L P E ®$ were used as external indicators, for determination of the values of the digestibility coefficient and of the digestible fraction of the nutritious principles, being this last one validated for use as indicator in ostriches. The total period of the experiment was twelve days, being seven days for the place and to the oxide chromic adaptation and five days for feces collection. There was not significant difference $(\mathrm{P}>0,05)$ between treatments for the values of the digestibility coefficient and digestible fraction of the nutritious principles (MS, MO, FDN, PB, EE e EB). Among the indicators, LPE® presented a smallercoefficient of variation in relation to the oxide chromic, forall of the appraised parameters. The most reliable values that are in accordance with the current literature were those estimated by the LIPE®. LIPE ${ }^{\circledR}$ was an excellent external indicator for ostriches in initial phase of growth.

Keywords: Apparent digestibility, Ostrich, Marker, Live yeast.

\section{Introdução}

O avestruz, Struthio camelus, é a mais antiga ave viva no planeta, podendo atingir $2,5 \mathrm{~m}$ de altura e $150 \mathrm{~kg}$ de peso quando adulto, dependendo da raça e sua localização geográfica, com expectativa de vida de 50 anos em média. A variedade doméstica atinge a maturidade sexual entre dois e três anos, sendo as fêmeas mais precoces. O dimorfismo sexual ocorre entre seis e dez meses de idade, sendo o macho com plumagem preta no corpo e branca na cauda e na ponta das asas, enquanto a fêmea se apresenta com a plumagem homogênea de cor acinzentada (SOUZA, 2004).

A nutrição e alimentação dessa espécie são uma incógnita, uma vez que a carência de pesquisas com essas aves faz com que haja uma extrapolação para a formulação das dietas, baseando-se na nutrição de outras espécies. Isso resulta em erros de formulação, causando grandes perdas na produção, principalmente, de filhotes, pois estes são sensíveis às mínimas alterações em sua dieta.

As exigências nutricionais dos avestruzes ainda não estão bem definidas, necessitando-se de mais pesquisas. Contudo, o uso de probióticos está sendo amplamente estudado, sua utilização é altamente recomendada e esse não apresenta efeitos colaterais para qualquer espécie animal. Isso se torna mais importante na nutrição dos filhotes de avestruz, pois nascem com o sistema digestório praticamente estéril e sua colonização se dará pela alimentação ou pelo ato de coprofagia.
Com este propósito, assim que o filhote nasce, ele recebe um probiótico à base de microrganismos durante os três primeiros dias de vida. No entanto, os filhotes com baixa resistência ficam facilmente doentes com qualquer desafio do qual são submetidos quando transferidos do berçário para o setor de cria, aos quatro dias de idade. Um manejo que conduza os filhotes a uma alta imunidade nesta fase é necessário e pode ser conseguido por meio de um fornecimento diário de probiótico.

A Saccharomyces cerevisiae é uma levedura de ampla utilização na indústria de cervejaria e no setor de panificação. É também amplamente utilizada em suplementos para a nutrição animal. Segundo Heugten et al. (2003), a suplementação da alimentação animal com leveduras tem a função de estimular a digestão e auxiliar a manutenção do equilíbrio microbiano do trato gastrointestinal de filhotes.

A digestibilidade dos princípios nutritivos é um bom indicador do quanto o animal pode processar os nutrientes derivados da sua dieta.

De acordo com Fernandes (2000), o avestruz tem uma digestão químico-enzimática muito importante no estômago e outra microbiana no intestino grosso (particularmente nos cecos que são bem desenvolvidos). Esses animais não têm capacidade para aproveitar a proteína microbiana, sendo essa totalmente eliminada pelas fezes, aproveitando apenas os ácidos graxos voláteis, ou seja, a energia.

Swart et al. (1993a, 1993b) citam que os avestruzes utilizam a fração fibrosa da planta, di- 
gerindo em parte as hemiceluloses e a celulose, isto dá uma contribuição substancial para energia metabolizável aparente (EMA) da dieta consumida. Os vertebrados são incapazes de sintetizar enzimas necessárias para digerir plantas fibrosas, mas muitos herbívoros, incluindo algumas aves, superam esta deficiência pela relação simbiótica com microrganismos intestinais (HERD; DAWSON, 1984; apud SWART, 1993a).

O tempo de retenção do alimento ou a taxa de passagem da digesta também são fatores que influenciam a digestibilidade do alimento. Salih et al. (1998) descobriram que dietas com alto teor de fibra reduzem significativamente o desempenho produtivo das aves durante a fase inicial. Durante o crescimento e acabamento foi observada a adaptação morfológica gradual no trato intestinal de aves alimentadas com elevados teores de fibra.

O maior tempo de retenção do alimento está associado ao aumento da absorção de água pelo intestino (WARNER, 1981; apud SWART et al., 1993). Complementando, Brand (2004) diz que o maior tempo de retenção do alimento faz com que haja maior disponibilidade para a ação das enzimas digestivas e dos microrganismos e, conseqüentemente, a dieta será mais digestível. Segundo Swart (1993a), a fermentação microbiana é influenciada pela estrutura, capacidade e conteúdo do trato gastrointestinal e contribui com o incremento de energia pela produção de ácidos graxos voláteis.

Mackie (1987) citado por Carbajo (1995) afirma que nos estudos realizados se evidenciou os processos de fermentação e a produção de AGV's no intestino grosso, mais particularmente nos cecos destas aves, sendo estes níveis similares aos encontrados em ruminantes, com pequenas variações na proporção de acetatos frente aos outros AGV's. Contudo, os ruminantes realizam a fermentação microbiana no rúmen, tendo um apro- veitamento da proteína microbiana proveniente dos microrganismos. Não ocorrendo o mesmo com 0 avestruz que realiza a fermentação no trato digestório posterior (cecos e intestino grosso) e não havendo trânsito suficiente para absorção desta proteína. Com isto, Carbajo (1995) supõe que o aproveitamento de proteína e aminoácidos é similar a outras aves.

A maioria das pesquisas em nutrição de avestruzes foi realizada na África do Sul. Vohra (1992) afirma que ao preparar uma dieta para avestruzes, algumas diretrizes necessitam ser pesquisadas além de estabelecer valores de energia metabolizável (EM) e proteína bruta (PB) para suprir os aminoácidos, bem como cálcio (Ca) e fósforo disponível $\left(\mathrm{P}_{\text {disp }}\right)$.

Neste contexto, objetivou-se avaliar a influência do concentrado de leveduras vivas sobre a digestibilidade dos princípios nutritivos na dieta de filhotes de avestruz em crescimento.

\section{Material e métodos}

Os animais foram selecionados ainda no incubatório, 36 dos 40 filhotes nascidos, que foram aleatoriamente distribuídos em dois grupos: tratamento controle (TC) e tratamento levedura (TL).

O valor dos nutrientes da ração fornecida pode ser visualizado na tabela 01 . Os ingredientes da composição básica da ração comercial, descritos no rótulo, foram: milho integral moído, farelo de soja, farelo de trigo, farelo de arroz, feno de alfafa, melaço, calcário calcítico, probiótico, metionina, fosfato bicálcico, colina, sal comum, lisina, premix mineral e vitamínico. A ração foi oferecida ad libitum em várias porções durante 0 dia e ao entardecer. As sobras foram pesadas e anotadas. Como volumoso foi oferecida couve picada. 


\section{TABELA 01 - Níveis dos princípios nutritivos analisados (base matéria natural) da ração comercial oferecida aos filhotes durante o período experimental}

Table 01 - Levels of the analyzed nutritional principles (natural matter) of the supplied commercial ration to the nestlings during the experimental period

\begin{tabular}{|l|r|}
\hline Nutrientes analisados & \\
\hline Energia bruta (kcal/kg) & $4.270,09$ \\
Proteína bruta (\%) & 21,67 \\
Fibra em detergente neutron (\%) & 30,20 \\
Extrato etéreo (\%) & 3,88 \\
Matéria mineral (\%) & 10,64 \\
Matéria seca (\%) & 89,28 \\
\hline
\end{tabular}

Durante o peńodo experimental, os filhotes tiveram acesso livre à água limpa, sendo no primeiro mês adicionado um suplemento vitamínico, comercialmente conhecido como Vitagold.

Foram realizados todos os procedimentos de rotina nos animais no incubatório, sendo transferidos para o setor de cria, aos quatro dias de idade, mantidos os tratamentos em piquetes separados e recolhidos ao anoitecer até os 60 dias; os filhotes passaram a ser mantidos no respectivo piquete externo, não sendo recolhidos ao anoitecer, devido nesta fase os filhotes já possuírem maior resistência.

Foi realizado um ensaio de digestibilidade ao final dos três meses, onde os piquetes foram subdivididos em baias de $8,75 \mathrm{~m}^{2}(3,5 \times 2,5 \mathrm{~m})$, nos quais alojaram-se três aves, de acordo com o esquema apresentado na figura 01. Para o ensaio de digestibilidade foram utilizados os seguintes indicadores externos: o óxido crômico e o LPE® para determinação dos valores do coeficiente de digestibilidade e fração digestível dos princípios nutritivos, sendo que este último está sendo validado para utilização como indicador em avestruzes. O período total do ensaio foi de doze dias, sendo sete dias de adaptação ao local e ao óxido crômico e cinco dias de colheita de fezes.

Os animais receberam duas cápsulas por dia (figura 02), uma contendo $100 \mathrm{mg}$ de LIPE® e outra contendo $500 \mathrm{mg}$ de óxido crômico $\left(\mathrm{Cr}_{2} \mathrm{O}_{3}\right)$. O LPE® foi fornecido a partir do sétimo dia do ensaio, tendo somente um dia de adaptação. Em seguida, foram colhidas amostras com cerca de 80 g de excretas de cada ave, durante cinco dias consecutivos.
Não foi possível separar a urina das fezes porque a urina nos avestruzes tem refluxo da cloaca para dentro do cólon onde é misturada com a digesta (SKADHAUGE, 1981 apud CILLIERS, 1998).

As fezes foram devidamente acondicionadas em sacos plásticos identificados, hermeticamente fechados e armazenados em congelador para posteriores análises químicas.

$O$ início do ensaio de digestibilidade culminou com o início do período chuvoso.

As amostras do alimento oferecido (ração) e das fezes colhidas foram analisadas segundo Cunniff (1995) para os seguintes nutrientes: matéria seca (MS), proteína bruta $(\mathrm{PB})$, fibra em detergente neutro (FDN), extrato etéreo (EE) e cinzas $(\mathrm{MM})$ e calculada a matéria orgânica (MO).

A técnica analítica para dosagem do indicador LIPE ${ }^{\circledR}$ nas fezes é a Espectroscopia no infravermelho (aparelho modelo Vatson Galaxy IVFT), e a determinação do cromo foi efetuada por Absorção Atômica modo de chama no aparelho CG AA 7000 SBC no Laboratório do Departamento de Engenharia Química da UFMG.

A produção fecal (PF) e o coeficiente de digestibilidade (CD) foram determinados por fórmulas e comparados com os resultados obtidos na leitura de recuperação do cromo, utilizando valores de ingestão de MS.

O procedimento para as análises estatísticas adotado foi o GLM do pacote estatístico SAS (Statistical Analysis System, 1995). 
FIGURA 01 - Modelo de divisória dos piquetes experimentais para 0 ensaio de digestibilidade. Figure 01 - Model of thick partition wall of the experimental poles for the digestibility assay.

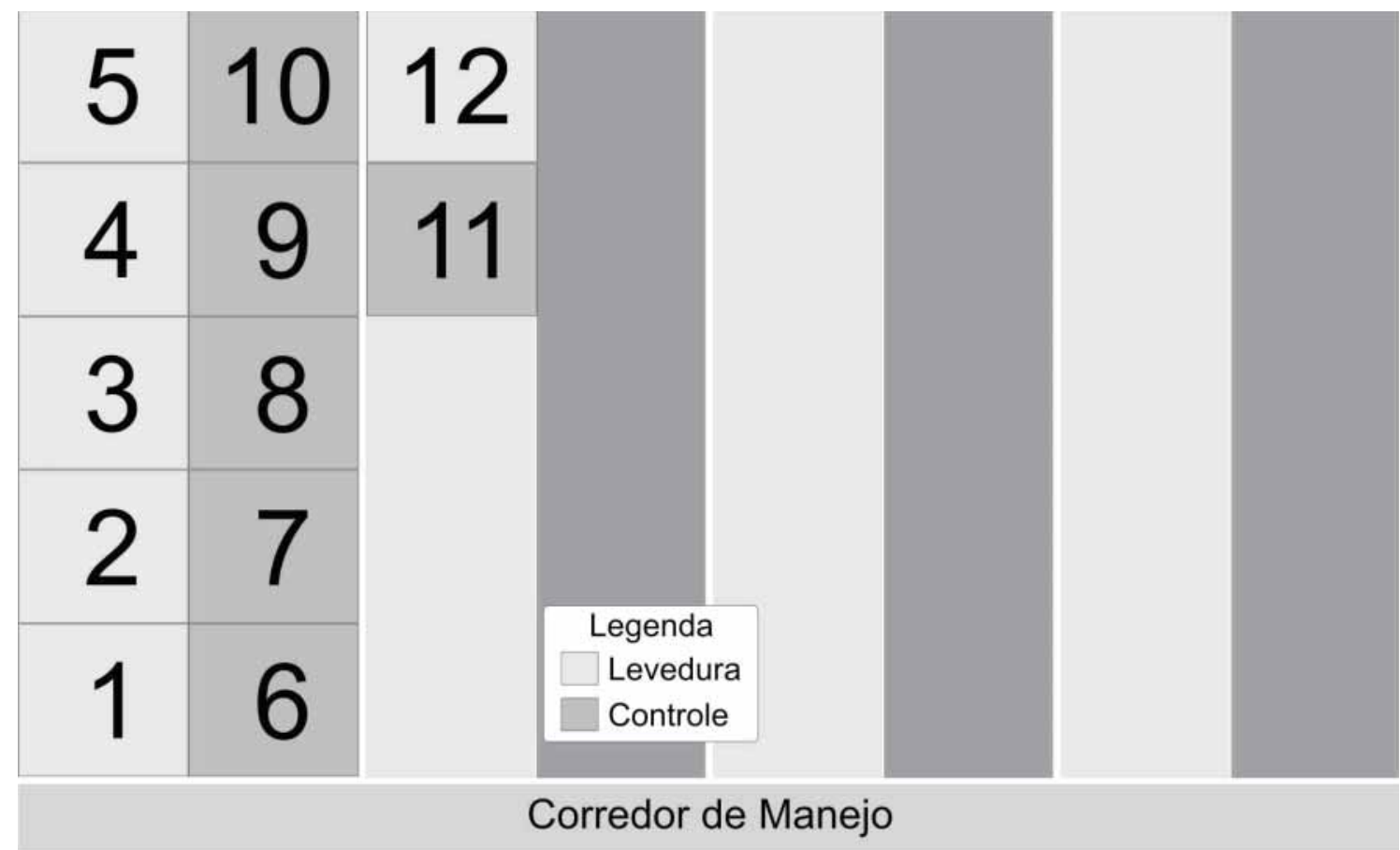

\section{Dormitório c/ cobertura}

FIGURA 02 - Cápsulas gelatinosas contendo os indicadores óxido crômico e LIPE®. Figure 02 - Gelatinous capsules containing chromic oxide and LPE® indicators.

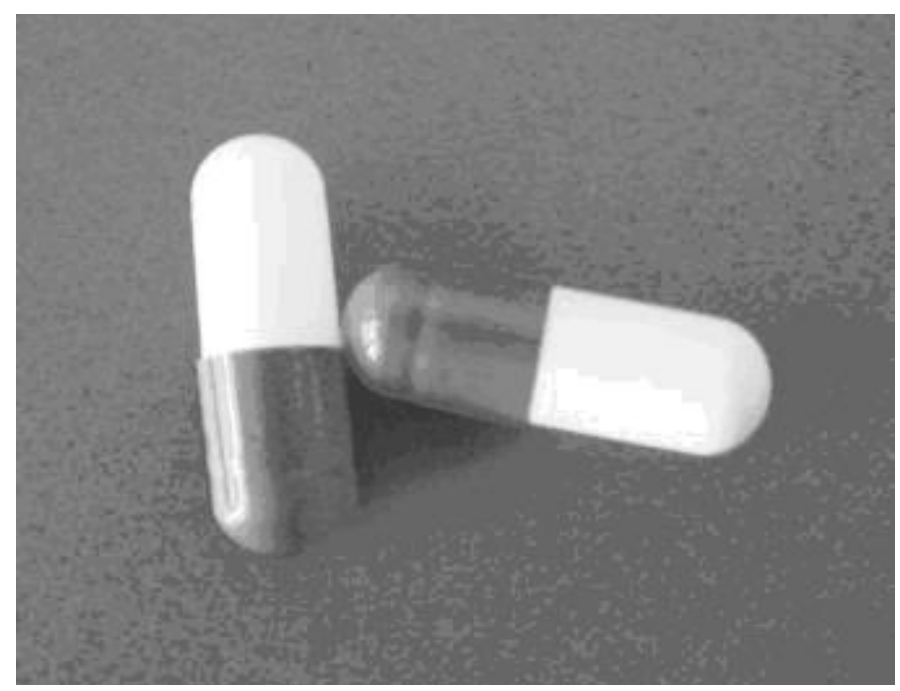




\section{Resultados e discussão}

Nas tabelas 02 e 03 encontram-se os valores do coeficiente de digestibilidade aparente
(CDa) dos princípios nutritivos. Os dados revelaram que não houve diferença significativa $(\mathrm{P}>0,05)$ nos tratamentos para os princípios nutritivos (MS, $\mathrm{MO}, \mathrm{FDN}, \mathrm{PB}, \mathrm{EE}$ e EB).

TABELA 02 - Coeficiente de digestibilidade da matéria seca (\% CDMS), matéria orgânica (\% CDM0), fibra em detergente neutro (\% CDFDN), proteína bruta (\% CDPB), extrato etéreo (\% $\mathrm{CDEE})$ e energia bruta ( $\mathrm{kcal} / \mathrm{kg} \mathrm{CDEB}$ ) estimados pelo óxido crômico.

Table 02 - Digestibility coefficient of the dry matter (\% CDMS), organic matter (\%CDMO), fiber in neutral detergent (\% CDFDN), total protein (\% CDPB), ethereal extract (\% $\mathrm{CDEE})$ and total energy ( $\mathrm{kcal} / \mathrm{kg} \mathrm{CDEB}$ ) esteemed by the chromic oxide.

\begin{tabular}{|l|l|l|l|l|l|l|}
\hline Tratamento & CDMS & CDMO & CDFDN & CDPB & CDEE & CDEB \\
\hline TC & 52,401 & 79,685 & 17,56 & 82,437 & 72,908 & 81,930 \\
TL & 49,095 & 77,820 & 17,01 & 81,300 & 71,694 & 80,533 \\
CV (\%) & 33,17 & 9,20 & 185,77 & 8,20 & 17,48 & 8,83 \\
\hline
\end{tabular}

*Não houve diferença significativa pelo teste $\mathrm{F}(\mathrm{P}>0,05)$

TABELA 03 - Coeficiente de digestibilidade da matéria seca (\% CDMS), matéria orgânica (\% CDM0), fibra em detergente neutro ( $\%$ CDFDN), proteína bruta ( $\%$ CDPB), extrato etéreo ( $\%$ CDEE) e energia bruta (kcal/kg CDEB) estimados pelo indicador LIPE® .

Table 03 - Digestibility coefficient of the dry matter (\% CDMS), organic matter (\% CDMO), fiber in neutral detergent (\% CDFDN), total protein (\% CDPB), ethereal extract (\%CDEE) and total energy (kcal/kg CDEB) esteemed by the LPE® indicator.

\begin{tabular}{|l|l|l|l|l|l|l|}
\hline Tratamento & CDMS & CDMO & CDFDN & CDPB & CDEE & CDEB \\
\hline TC & 71,603 & 87,639 & 50,065 & 89,296 & 83,171 & 89,377 \\
TL & 72,311 & 87,741 & 54,290 & 89,635 & 83,249 & 89,290 \\
CV (\%) & 8,11 & 3,61 & 28,65 & 3,86 & 10,80 & 3,51 \\
\hline
\end{tabular}

*Não houve diferença significativa pelo teste $\mathrm{F}(\mathrm{P}>0,05)$

Heugten et al. (2003) avaliaram o desempenho produtivo de crescimento, digestibilidade de nutrientes e microflora fecal em suínos desmamados alimentados com levedura viva. Estes autores não encontraram efeito significativo para a digestibilidade dos nutrientes com a suplementação.

Swart (1993) encontrou um valor de digestibilidade da MS de 71,7\% quando os animais se encontraram numa faixa de peso de 15 a $18 \mathrm{~kg}$ de peso vivo. Estes dados encontram-se de acor- do com os valores encontrados neste ensaio pelo LIPE®. No entanto, o óxido crômico subestimou este valor, apresentando um maior coeficiente de variação $(33,17 \%)$ em relação ao encontrado pelo LPE® $(8,11 \%)$.

Não há dados de trabalhos com relação ao coeficiente de digestibilidade de matéria orgânica para avestruzes. Contudo, o LPE® apresentou um coeficiente de variação menor $(3,61 \%)$ em relação ao óxido crômico (9,20\%). 
Os valores do CDFDN estimados pelo LIPE® estão de acordo com os encontrados por Swart (1993), que obteve uma digestibilidade de 43,7\% de FDN, e em filhotes pesando entre 15-18 $\mathrm{kg}$ de peso vivo, utilizando cromo marcado como indicador. Esta alta digestibilidade está relacionada à digestão microbiana no intestino grosso dos avestruzes. Assim como Angel (1993), que avaliando a digestibilidade dos nutrientes nas diferentes etapas de crescimento dos avestruzes, encontrou uma digestibilidade de FDN de 51,2\% para avestruzes com dez semanas de idade.

O CDFDN estimado pelo óxido crômico teve um coeficiente de variação maior que 100, o que demonstra a alta instabilidade dessa variável. Contudo, o LPE® teve um coeficiente de variação de 28,65, para este parâmetro.

Cilliers (1997), em um estudo comparativo entre avestruzes maduros e galos adultos, con- siderando a digestibilidade aparente e verdadeira de aminoácidos, encontrou uma digestibilidade aparente de proteína de 65,3\%.

O CDEE estimado pelo óxido crômico foi de 71 a $72 \%$, enquanto que o estimado pelo LIPE® foi de 83\%, valor este que mais se aproxima ao encontrado por Angel $(1993,1996)$ que foi de $85,7 \%$ de digestibilidade de gordura em avestruzes com dez semanas de idade.

$\mathrm{O}$ valor de EM, para avestruzes com 10 semanas de idade, encontrado por Angel (1993) foi de $2684 \mathrm{kcal} / \mathrm{kg}$.

Não houve diferença significativa $(\mathrm{P}>0,05)$ para a fração digestível dos princípios nutritivos estudados, conforme pode ser visualizado nas tabelas 04 e 05 . Contudo, o coeficiente de variação do estimado pelo óxido crômico foi maior que o coeficiente de variação dos dados estimados pelo LIPE®.

TABELA 04 - Fração digestível da matéria seca (\% MSDa), proteína digestível (\% PDa), do extrato etéreo (\% EEDa) e da energia digestível (kcal/kg EDa) estimada pelo óxido crômico.

Table 04 - Digestible fraction of the dry matter (\% MSDa), digestible protein (\% PDa), of the ethereal extract (\% EEDa) and of the digestible energy (kcal/kg EDa) esteemed by the chromic oxide.

\begin{tabular}{|l|l|l|l|l|}
\hline Tratamento & MSDa & PDa & EEDa & EDa \\
\hline TC & 46,782 & 15,9517 & 2,5220 & $3.123,46$ \\
TL & 43,831 & 15,7317 & 2,4800 & $3.070,17$ \\
CV $(\%)$ & 33,17 & 8,20 & 17,48 & 8,83 \\
\hline
\end{tabular}

*Não houve diferença significativa pelo teste $\mathrm{F}(\mathrm{P}>0,05)$.

TABELA 05 - Fração digestível da matéria seca (\% MSDa), proteína digestível (\% PDa), do extrato etéreo (\% EEDa) e da energia digestível (kcal/kg EDa) estimada pelo indicador LIPE®.

Table 05 - Digestible fraction of the dry matter (\% MSDa), digestible protein (\% PDa), of the ethereal extract (\% EEDa) and of the digestible energy (kcal/kg EDa) esteemed by the LPE® indicator.

\begin{tabular}{|l|l|l|l|l|}
\hline Tratamento & MSDa & PDa & EEDa & EDa \\
\hline TC & 63,925 & 17,2789 & 2,8770 & $3.407,35$ \\
TL & 64,557 & 17,3446 & 2,8797 & $3.404,04$ \\
CV $(\%)$ & 8,11 & 3,86 & 10,80 & 3,51 \\
\hline
\end{tabular}

*Não houve diferença significativa pelo teste $\mathrm{F}(\mathrm{P}>0,05)$. 


\section{Conclusões}

De acordo com os resultados obtidos nas condições em que foram realizados os ensaios, pode-se concluir que os coeficientes de digestibilidade e as frações digestíveis dos princípios nutritivos da dieta não foram influenciados pela suplementação do concentrado de leveduras vivas.

\section{Agradecimentos}

À SAF do BRASIL pelo apoio concedido. À CAPES pela concessão da bolsa. Ao criatório Aveluz e aos associados da ACRIA.COM pela cessão dos animais e das instalações para realização do experimento.

\section{Referências}

ANGEL, C. R. Research update: Age changes in digestibility of nutrients in ostriches and nutrients profiles of ostrich and emu eggs as indicators of nutritional status of the hen and chick. Proc. Assoc. of Avian Veterinarians, Nashville, September, 1993. p. 275-281.

ANGEL, C. R. A review of ratite nutrition. Animal Feed Science Technology, v. 60, p. 241-246, 1996.

BRAND, T. The potential of ostriches to utilize high fibre diets. Animal Feed Manufacturers Association. Ostrich Research Unit. Elsenburg. Disponível em: www.afma.co.za. Acesso em: 20 jul. 2004.

CARBAJO , E. Características Anatomicas y Fisiológicas. Metabolismo. Comportamiento. Hematologia. In: CARBAJO , E.; GURRI, A., MESIÀ, J., CASTELLÓ, F. Cria de Avestruces. Espanha: Real Escuela de Avicultura, 1995. p. 27-47.

CILUERS, S. C.; HAYES, J. P.; CHWALIBOG, A. etal. A comparative study between mature ostriches (Struthio camelus) and adult cockerels with regard to the true and apparent digestibilities of amino acids. Short communication. Brit. Poult. Sci. v. 38, p. 311-313, 1997.

CILUERS, S. C.; HAYES, J. P.; CHWALBBOG, A.; SALES, J.; DU PREEZ, J. J. Determination of energy, protein and amino acid requirements for maintenance and growth in ostriches. Animal Feed Science Technology, v. 72, p. 283-293, 1998. CUNNIFF, P. (Ed.) Official methods of analysis of AOAC International. 16. ed. Arlington: AOAC International, 1995. v. 1.

FERNANDES, C. C. Produção de avestruz. Alqueva: Baronigg,. 2000. p. 74.

HEUGTEN, E. van; FUNDERBURKE, D. W.; DORTON, K. L. Growth performance, nutrient digestibility, and fecal microflora in wealing pigs fed live yeast. J. Anim. Sci. v. 81, p. 1004-1012, 2003.

SALH, M. E.; BRAND, T. S.; VAN SCHALKWYK, S. $\mathrm{J}$. et al. The effect of dietary fibre level on the production of growing ostriches. In: INTERNATIO NAL RATITE CONGRESS. 2., Oudtshoorn, 1998. Proceedings... Oudtshoorn: [s. n.], 1998. p31-37.

SAS INSTITUTE. SAS user's guide: statistics. Cary, Sas Institute. 1995. p. 956.

SOUZA, J. D. S. Criação de avestruz. Viçosa: Aprenda Fácil, 2004. p. 211.

SWART, D.; MACKIE, R. I.; HAYES, J. P. Influence of live mass, rate of passage and site of digestion on energy metabolism and fibre digestion in the ostrich (Struthio camelus var. domesticus). South African Journal of Animal Science, v. 23, n. 5/6, p. 119126, 1993.

SWART, D.; MACKIE, R. I.; HAYES, J. P. Fermentative digestion in the ostrich (Struthio camelus var. domesticus), a large avian species that utilizes cellulose. South African Journal of Animal Science, v. 23, n. 5/6, p. 127-135, 1993a.

SWART, D.; SIEBRITS, F. K.; HAYES, J. P. Utilization of metabolizable energy by ostrich (Struthio camelus) chicks at two different concentrations of dietary energy and crude fibre originating from leucerne. South African Journal of Animal Science, v. 23, n. 5/6, p. 136-141, 1993b.

VOHRA, P. Information on ostrich nutritional needs still limited. Feedstuffs, v. 64, n. 28, p. 16-17, july, 1992.

Recebido em: 08/12/2004 Aprovado em: 30/06/2005 